\title{
Mathematical Modeling of the Colloidal Gas Aphron Transport through Porous Medium Using the Filtration Theory
}

1- Ali Alizadeh

Email :(alizadeh2627@aut.ac.ir)

Faculty of the Petroleum Engineering, Amirkabir University of Technology (Tehran Polytechnic)

2- Ehsan Khamehchi

Corresponding Author

Email :(khamehchi@aut.ac.ir)

Faculty of the Petroleum Engineering, Amirkabir University of Technology (Tehran Polytechnic)

(C) 2017. This manuscript version is made available under the Elsevier user license http://www.elsevier.com/open-access/userlicense/1.0/ 


\title{
Mathematical Modeling of the Colloidal Gas Aphron Transport through Porous Medium Using the Filtration Theory
}

\begin{abstract}
Recently, Colloidal Gas Aphron fluids, which includes micro-bubbles in a based fluid, have been successfully employed in drilling depleted reservoirs or formations which had previously experienced huge fluid losses. Aphron bridging in the front of the porous media in near wellbore zone, reduces the formation damage and fluid depth of invasion into the formation. Although more experimental investigation is carried out on Aphron fluid filtration, a few modeling works were performed in the literature. In this work, the filtration theory approach is used to mathematically model the Aphron transport in porous medium. Several physical/chemical parameters including surfactant type, surfactant concentration, temperature, rock porosity and permeability, grain and bubble size, and pressure, were investigated. Results from the modeling suggest that retention of Aphrons could be adequately described by the filtration theory.
\end{abstract}

Keywords: Modeling, Porous Media, Filtration Theory, Colloidal Gas Aphron, Surfactant

\section{Introduction}

For the first time Sebba introduced the Aphrons (Sebba, 1987). According to him, Aphrons are micro dispersed bubbles, in a range of 10-100 microns in diameter. They are made up of a spherical gas core, covered by a thin aqueous layer. This layer consists of liquid which has two surfaces. Aphron colloidal properties rise from surfactant molecules at the thin layer (Sebba, 1987). Colloidal gas Aphrons are different from foams not only in structure, but also in rheological and stability properties. Bubbles in Aphron fluids are stabilized by using a layer of polymer/surfactant. According to Figure 1a, the inner layer consists of surfactant which covers and separates the gas core from the viscous layer. A 
conventional foam bubble, as in Figure $1 \mathrm{~b}$, is a sphere of gas separated from its bulk fluid with thin film.

Recently, Aphron fluids have been successfully employed in drilling depleted reservoirs or formations which had previously experienced huge fluid losses (Brookey, 1998)(Ivan et al., 2001)(Ramirez et al., 2002)(Rea et al., 2003)(Bjorndalen and Kuru, 2008). Brookey was the first one who introduced Aphrons for horizontal well drilling. Some problems such as uncontrollable fluid loss and need for injection of lost circulation material for controlling the fluid loss, imposes high formation damage while drilling of low pressure or depleted reservoirs. Minimizing these problems, the unconventional and underbalance drilling operation have to be applied in case of depleted/low pressure reservoirs drilling. This method improves drilling performance by reducing drilling fluid invasion into the formation while drilling operation (Brookey and Rea, 2003)(White et al., 2003) Using Aphron fluids reduced circulation losses with around $10 \%$ reduction in the drilling operation time(Ivan et al., 2001)(Brookey and Rea, 2003).

Aphron fluids, for using in underbalanced drilling operation are easily created with typical mud mixing equipment. From the other hand, the costs which must paid for compressors and equipment employed in foam drilling operation eliminated in case of Aphron fluid drilling operation (White et al., 2003)There is no corrosion issues of drill string and related equipment in case of using Aphron drilling fluids, since most of air in the system is trapped in Aphron shell (Bjorndalen and Kuru, 2008).

Recently, Ahmadi investigated rheology and filtration loss properties of Aphron fluids in presence of natural surfactants, derived from Henna leaves and Seidlitzia Rosmarinus root (Ahmadi et al., 2015). Khamehchi (Khamehchi et al., 2016) worked on the rheological behavior of Aphron drilling fluid using various rheological models and in different temperatures, choosing the most accurate model to investigate fluid flow behavior.

Aphron can also be used for balanced drilling. In this type of drilling operation, fluid pressure must be maintained at a higher level than the formation pressure, but the pressure difference must not be so high to avoid fluid invasion into the formation rock 
(Belkin et al., 2005). Although more experimental investigation is carried out on Aphron fluid filtration and its related parameters (Sebba, 1987)(Brookey, 1998)(Ivan et al., 2001)(Ramirez et al., 2002)(Rea et al., 2003)(Bjorndalen and Kuru, 2008), a few modeling works were carried out in the literature (Belkin et al., 2005), recently Alizadeh and Khamehch have published some works on the Aphron modeling and flow through porous medium (Alizadeh and Khamehchi, 2015a)(Alizadeh and Khamehchi, 2015b)(Alizadeh and Khamehchi, 2016a)(Alizadeh and Khamehchi, 2016b)(Alizadeh and Khamehchi, 2016c)

When a solid free fluid is created due to environmental issues, the use of Aphron drilling

fluids is considered. Bridging in the front of the porous media in near wellbore zone, in fractured or depleted reservoirs, reduces the formation damage and fluid depth of invasion into the formation. Entered micro bubbles to the formation, may be removed at the start of production period due to low capillary pressure between Aphron and produced reservoir fluids (Belkin et al., 2005).

\section{Mathematical Modeling}

\subsection{Mass Transfer Modeling}

Fick's second law is used to model the mass transfer through layers of surfactant covering the bubble. Figure 2 shows a typical Aphron bubble scheme.

The Langmuir Isotherm was used for description of the surfactant adsorption. Note that the size of the bubble is not constant during time(Alizadeh and Khamehchi, 2017).

The mass transfer partial differential equation (Alizadeh and Khamehchi, 2016a) (Alizadeh and Khamehchi, 2015b)(Alizadeh and Khamehchi, 2016c) for each layer of the bubble is as equation 1:

$\frac{\partial C_{i}}{\partial t}=D_{i}\left[\frac{1}{r^{2}} \frac{\partial}{\partial r}\left(r^{2} \frac{\partial C_{i}}{\partial r}\right)\right]$ 
where $i$ is the layer index (Figure 2), $C$ is the surfactant concentration in time of $t$ and space of $\mathrm{r}$, and $D$ is the diffusion coefficient.

The interfacial resistance of each interface $(j=1, j=2$ in the Figure 2$)$ is the inverse value of the interfacial mass transport coefficients $\left(\mathrm{k}_{\mathrm{j}}\right)$. The flux of the mass transport through interfaces $\left(\mathrm{N}_{\mathrm{Aj}}\right)$ is given by equation 2 :

$$
\begin{gathered}
N_{A j}=k_{j}\left(\left(\frac{C_{j-1}}{m}\right)_{r=R_{j}^{-}}-\left(C_{j+1}\right)_{r=R_{j}^{+}}\right)=-D_{j+1}\left(\frac{d C_{j+1}}{d r}\right)_{r=R_{j}^{+}} \\
=-D_{j-1}\left(\frac{d C_{j-1}}{d r}\right)_{r=R_{j}^{-}}
\end{gathered}
$$

Where, $\mathrm{m}$ is the partitioning coefficient. There are three layers ( $\mathrm{i}$ index) and two interfaces ( $\mathrm{j}$ index) in the Aphron bubble, so the five equations must be solved simultaneously. The boundary and initial conditions of the differential equations are listed in Table 1.

The interfacial mass transport coefficient can be estimated as below (Alizadeh and Khamehchi, 2016a) (Alizadeh and Khamehchi, 2015b)(Alizadeh and Khamehchi, 2016c);

$k=H\left[\sigma_{0}-n R^{\prime} T \Gamma_{m} \ln (1+C K)\right]$

where, $\mathrm{K}$ is the Langmuir equilibrium constant and $\Gamma_{\mathrm{m}}$ is the maximum reachable surface concentration.

The Patankar control volume (Suhas Patankar, 1980) is used to solve one-dimensional partial differential equations. For achieving greater precision results, 0.005 second time step is used and, for obtaining high resolution results, the number of grids in core, shell, and bulk fluid are chosen as 500, 50, and 700, respectively. This selection of grid numbers and time steps length will be enough to achieve precise results for the present work. For the first and second order space 
derivatives, the following discrete forms of the finite difference (Taylor approximation) were used. For the first order space derivative, explicit central approximation was used as below:

$\left.\frac{\partial C}{\partial r}\right)_{i}^{t}=\frac{C_{i+1}^{t}-C_{i-1}^{t}}{2 \Delta r}$

and, for the second order space derivative:

$\left.\frac{\partial^{2} C}{\partial r^{2}}\right)_{i}^{t}=\frac{C_{i+1}^{t}-2 C_{i}^{t}+C_{i-1}^{t}}{\Delta r^{2}}$

At constant position, the concentration function may be expanded in forward direction in regard to time:

$\left.\frac{\partial C}{\partial t}\right)_{i}^{t}=\frac{C_{i}^{t+\Delta t}-C_{i}^{t}}{\Delta t}$

Where $\mathrm{i}$ and $\mathrm{t}$ are space and time index, respectively. Obviously, the explicit formulation is simpler than the implicit formulation to apply. Discretization errors for both formulations are the same but for the explicit case, the amount of work involved is less. In one-dimensional solutions, this is inconsequential, whereas, in two and three dimensional cases especially with large numbers of grid blocks, the difference in computational time per time step will become large. However, the explicit formulation is seldom used. As it turns out, it becomes unstable for large time steps. It will be shown below, using von Neumann stability analysis, that the explicit formulation has the following stability requirement:

$\Delta t \leq \frac{1}{2} \times D_{i} \times \Delta r^{2}$

So time step size is limited by both grid block size and mass transfer properties. 
In addition to mass transfer through surfactant layers, pressure and temperature also have an influence on the size of Aphron. Over time, the mass transfer phenomenon appears between layers, due to concentration differences between them, and the size of the Aphron bubble reduction. For estimating the Aphron bubble size, the average density of the bubble is calculated in each time-step, using surfactant layer thickness, surfactant, and core densities. Afterwards, solving the diffusion equations for layers, the output mass from the bubble is calculated, so the average density of the bubble for any time step is predicted. The instantaneous mass of the bubble is calculated by the following mass balance equation (Alizadeh and Khamehchi, 2015b)(Alizadeh and Khamehchi, 2016c):

mass $_{t}=$ mass $_{t-1}-$ mass $_{\text {exit }}$

Where, mass exit $_{\text {and }} \mathrm{t}$ are the exited mass and time, respectively. Inserting the density definition in Equation 4:

$(\rho V)_{t}=(\rho V)_{t-1}-(\rho V)_{e x i t}$

All parameters values at the last step ( $\mathrm{t}-1)$ are known, mass $\mathrm{exit}_{\mathrm{t}}$ is calculated by the equation of diffusion, and average density at time $t$ is also calculated. So, the current volume of the bubble is calculated using Equation 6:

$V_{t}=\frac{(\rho V)_{t-1}-\text { mass }_{\text {exit }}}{\rho_{t}}$

Thus, the radius of the spherical bubble is calculated.

The effect of pressure and temperature on the bubble size is calculated by the real gas equation of state. The Beggs and Brill's (Golan and Whitson, 1991) method is thus applied for the gas compressibility factor (Z-factor) estimation. Sutherland's model was 
applied to calculate the dynamic viscosity of gases, which is a function of the temperature (Smits and Dussauge, 2006).

$\mu=\mu_{0} \frac{T_{0}+S}{T+S}\left(\frac{T}{T_{0}}\right)^{1.5}$

where $\mathrm{S}$ is Sutherland's constant for the gaseous material (120 K for air). In liquids, the viscosity model is different due to additional forces between the molecules. In liquids, viscosity is relatively pressure independent and tends to fall as temperature increases. Thus, the effect of temperature on bulk fluid (water) viscosity (Golan and Whitson, 1991)is obtained by correlation 8 :

$\mu=A_{w} \cdot 10^{\frac{B_{w}}{T-C_{w}}}$

where $A_{w}, B_{w}$, and $C_{w}$ are equation constants.

Surfactant viscosity is calculated using the following equation (Wang et al., 2004):

$\mu=\mu_{0} \exp \left(\frac{A_{1}\left(T-T_{0}\right)}{A_{2}+\left(T-T_{0}\right)}\right)$

where $\mathrm{A}_{1}$ and $\mathrm{A}_{2}$ are experimental constants.

The temperature influence on the interfacial tension and diffusion coefficients is evaluated by Gibbs law in the presence of Langmuir adsorption and the Stokes-Einstein equation, respectively.

\subsection{Fluid Flow Modeling}


Aphron transport through the porous medium may be assumed as a type of colloidal flow. The one dimensional flow equation, through a homogeneous porous medium, is given by (Selim and Mansell, 1976):

$$
R \frac{\partial C}{\partial t}=D \frac{\partial^{2} C}{\partial x^{2}}-v_{0} \frac{\partial C}{\partial x}-k_{a} C
$$

where $\mathrm{C}$ is the Aphron concentration, $\mathrm{t}$ is time, $\mathrm{x}$ is space, $\mathrm{R}$ is the retardation coefficient for local sorption equilibrium, $\mathrm{k}_{\mathrm{a}}$ is the pseudo first-order rate coefficient, $\mathrm{D}$ is the dispersion coefficient $\left(D=v_{0} \alpha_{L}\right), \alpha_{L}$ is the longitudinal dispersivity and $\mathrm{v}_{0}$ is velocity of the pore water. The final discretized finite difference center point scheme with forward differencing in time assuming concentration harmonic time-dependency of Equation 10a is:

$$
\begin{aligned}
& \frac{C_{i}^{n+1}-C_{i}^{n}}{\Delta t^{n}}=\frac{\left[\alpha_{i-\frac{1}{2}}^{n} C_{i-1}^{n}-\beta_{i-\frac{1}{2}}^{n} C_{i}^{n}\right]-\left[\alpha_{i+\frac{1}{2}}^{n} C_{i}^{n}-\beta_{i+\frac{1}{2}}^{n} C_{i+1}^{n}\right]}{\Delta x_{i}}-\frac{k_{a}}{R} C_{i} \\
& \alpha_{i}=\frac{\frac{v_{0}}{R} E_{i+\frac{1}{2}}}{E_{i+\frac{1}{2}}-E_{i-\frac{1}{2}}}, \quad \beta_{i}=\frac{\frac{v_{0}}{R} E_{i-\frac{1}{2}}}{E_{i+\frac{1}{2}}-E_{i-\frac{1}{2}}}, \\
& E_{i-\frac{1}{2}}=\exp \left[\frac{v_{0}}{D}\left(x_{i}-x_{i-1}\right)\right], \quad E_{i+\frac{1}{2}}=\exp \left[\frac{v_{0}}{D}\left(x_{i+1}-x_{i}\right)\right]
\end{aligned}
$$

Where $\mathrm{n}$ and $\mathrm{i}$ are time counter space counter, respectively.

Assuming linear adsorption, the retardation coefficient is given by the following equation:

$$
R=1+\frac{\rho_{\text {bulk }} k_{1}}{\varepsilon}
$$

where $\rho_{\text {bulk }}$ is the density of the dry porous medium, $\varepsilon$ is the porosity of the porous medium and $k_{1}$ is the distribution constant. 
In general, for short-term fluid transport through the porous medium without any increase in the pressure level, the dissolution can be assumed negligible. In this work, for the initial step of the calculations, the size of the bubbles are assumed constant, and then using mass transfer equations through Aphron, surfactant layers of the bubble dissolution in the presence of the bulk fluid are considered. Any change in thermodynamic conditions and surfactant type can change the size of the Aphron due to mass transfer through Aphron layers, and compressibility of the Aphron gas core. The surfactant layers are assumed incompressible in this study.

The following initial and boundary conditions are applied for solving the partial differential equation (PDE) of equation 10:

$$
\begin{aligned}
& C(x, t)=0, \quad t=0 \\
& C(x, t)=\left\{\begin{array}{llr}
C_{0}, & x=0 ; 0<t \leq t_{0} \\
0, & x=0 ; & t>t_{0}
\end{array}\right. \\
& \frac{\partial C(x, t)}{\partial x}=0, \quad x=L
\end{aligned}
$$

where $\mathrm{C}_{0}$ is the inflow concentration, and $\mathrm{t}_{0}$ is the pulse injection duration time of the Aphron, respectively. Equations 10 and 12 can be solved by adjusting three parameters of the $\mathrm{D}, \mathrm{R}$, and $\mathrm{k}_{\mathrm{a}}$. Two approaches can be considered for modeling Aphron transport in the porous medium (Martinus Th. Van Genuchten and WJ Alves, 1982). In the first one, three parameters of $\mathrm{D}, \mathrm{R}$, and $\mathrm{k}_{\mathrm{a}}$ were used as adjustable parameters to fit the data to equation 10 by applying the modified Levenberg-Marquardt nonlinear regression (Martinus Th. Van Genuchten and WJ Alves, 1982). In the second approach, $\mathrm{k}_{\mathrm{a}}$ is estimated based on the filtration theory. Here the major assumption is the rigid behavior of the Aphron bubbles which are coated by surfactant layers. In other words, there is not any breakage of the Aphron bubbles. Using filtration theory, the pseudo first-order rate coefficient $\mathrm{k}_{\mathrm{a}}$, is correlated by the filtration coefficient of $\lambda$ (Yao et al., 1971): 


$$
k_{a}=v_{0} \lambda=v_{0}\left[\frac{3}{2} \frac{(1-\varepsilon) \alpha \eta}{d_{g}}\right]
$$

where the $d_{g}$ is the equivalent grain diameter of the porous medium. The porous medium efficiency of $\eta$, is defined as the ratio of the rate at which particles strike the porous medium to the rate at which particles flow toward the porous medium. The collision efficiency factor $\alpha$, is defined as a fraction of the particle collisions which result in particle attachment to the porous medium. In the case of good surface interaction between particles and porous medium, the value of $\alpha$ approaches unity, while in the poor surface interaction between porous medium and existing particles, $\alpha$ approaches zero. In this work, Aphrons are negatively charged similar to porous medium grains, so the value of the $\alpha$ may be too low or negligible for further calculations.

The coefficient $\eta$ can be specified by considering the transport mechanism such as inertial impact, gravity, diffusion, and electrostatic forces. The rate of the particles through the porous medium decreases when the streamlines of the fluid intercept by the porous medium, so some of the bubbles cannot enter into the pores of the media, and result in cake formation. Since the grain sizes of the porous medium for this study are always larger than Aphron micro bubbles, the cake formation may be insignificant. There is no inertial impact because of the low density of the Aphron bubbles in comparison to the bulk fluid.

There are several methods in the literature to calculate the coefficient of $\eta$ (Yao et al., 1971). In this study, both the grains of the porous medium and Aphron bubbles were assumed in spherical shape, so the Rajagopalan and Tien (Rajagopalan and Tien, 1976)(Samuel et al., 2012) method, which takes into account the effect of neighboring grain on each other, and contribution of London-van der Waals attractive forces, is used to calculate the $\eta$ value (Samuel et al., 2012).

Rajagopalana and Tien proposed the following correlation for the porous medium efficiency $(\eta)$ : 


$$
\begin{aligned}
& \eta=\left[4 A_{s}^{\frac{1}{3}} N_{P e}^{-\frac{2}{3}}+A_{s} N_{L o}^{\frac{1}{8}} N_{R}^{\frac{15}{8}}+0.00338 A_{s} N_{G}^{1.2} N_{R}^{-0.4}\right] \\
& N_{R}=d_{p} / d_{g} \\
& N_{P e}=\frac{U D_{c}}{\left[\frac{k T}{e \pi \mu d_{p}}\right]} \\
& N_{G}=\frac{U_{p}}{U} \\
& N_{L o}=\frac{4 H}{9 \pi \mu d_{p}^{2} U} \\
& A_{S}=\frac{2\left(1-\gamma^{5}\right)}{2-3 \gamma+3 \gamma^{5}-2 \gamma^{6}} \\
& \gamma=(1-\varepsilon)^{\frac{1}{3}}
\end{aligned}
$$

where $d_{p}$ is the bubble (particle) diameter, $U$ is the fluid approaching velocity, $k$ is the Boltzmann constant, $\mathrm{T}$ is the temperature, $\mu$ is the fluid dynamic viscosity, $U_{p}$ is the particle setteling velocity, and $\mathrm{H}$ is the Hamakar constant which is assumed about $10^{-20} \mathrm{~J}$. Since the density of the Aphron bubbles are less than the bulk fluid density, the settling of the particles (bubbles) will not occur. Instead, the bubbles rise to the fluid surface. Thus, the Stokes law for estimation of the bubble rising velocity can be applied:

$$
U_{p}=\frac{g \rho_{f} d_{p}^{2}}{18 \mu}
$$

where, $g$ is the gravitational acceleration, and $\rho_{f}$ is fluid density. To calculate" $\eta "$, using equation 14 , the $\mathrm{k}_{\mathrm{a}}$ value has to be evaluated, which is required for estimation of the" $\alpha$ ". Having three values of $\mathrm{k}_{\mathrm{a}}, \eta$, and $\alpha$, the partial differential equation of 1 is solved. For solving equation 10 , in the first step, diffusion equations of section 2.1 at the desired pressure and temperature conditions must be solved. Darcy's equation is used for fluid flow through porous medium calculation. During the flow through porous medium, the 
concentration of the fluid in any section of the porous medium is changed, which indicates the filtration distance of the Aphron fluid.

The overall flowchart of modeling is shown in Figure 3, in which, the $\mathrm{N}_{\mathrm{x}}$ and $\mathrm{N}_{\mathrm{t}}$ are grid numbers in time and space. As shown in Figure 3, all the equations are solved initially for each space grid, where the space counter of the xi is increased in each loop to cover the all of the space grids; afterward the time counter of ti is increased to cover time duration which user request for modeling; this increasing in time is continued till reaching the end of modeling time (criteria $t i<\mathrm{N}_{\mathrm{t}}$ ), which is entered by user as a data.

\section{Model Verification}

The model proposed here were validate with Shivana (Samuel et al., 2012) experiments. Shivana used a visual cell which has just one injection and one production ports to investigate the Aphron fluid infiltration through a 10-100 microns glass bead pack, using a visual cell. The visual cell was $20 \mathrm{~cm}$ in length and $3.81 \mathrm{~cm}$ in both width and height. Due to having just one entrance and one exit ports, the flow is linear. The results of experiments with of $2 \mathrm{lb} / \mathrm{bbl}(2 \mathrm{~g} / 350 \mathrm{cc})$ xanthan gum bi-polymer, $1 \mathrm{lb} / \mathrm{bbl}(1 \mathrm{~g} / 350)$ sodium dodecyl benzene sulfonate surfactant, mixed with fresh water (Selim and Mansell, 1976), and a pressure difference of $200 \mathrm{psi}$, using a porous medium with porosity and permeability of $10 \%, 100 \mathrm{mD}$, respectively, were used for verification. Figure 4 shows the modeling results of fluid infiltration depth through porous medium.

\section{Results and Discussion}

In this section, for investigating the Aphron fluid filtration, the effect of physical and thermodynamic conditions is investigated. Surfactant concentration, bubble and grain size range, temperature, pressure, porosity and permeability of the rock are taken into account for sensitivity analysis, using a predefined base case. The properties of the base case are presented in Table 2.

\subsection{Effect of Surfactant Concentration}


For investigating the surfactant concentration effect on the Aphron flow through porous medium, five concentrations of $0.1,0.5,1,1.5$, and $2 \mathrm{~g} / \mathrm{cc}$ were analyzed. The results are shown in Figures 5 and 7. According to Figure 5, the concentration of the surfactant in the core increases during time and filtration of the fluid. For example, after a $2 \mathrm{~min}$ injection, the front of the fluid in the core for the base case reached $18 \mathrm{~cm}$. Concentration

of the surfactant in the non-invaded zone in the core is zero. With the passage of time, the Aphron fluid breakthrough, and the concentration of the surfactant in its end face increases, but never reaches the surfactant initial concentration due to blocked pores. According to Figure 6a, in a fixed point of the core the concentration increases nonlinearly with time. Figure $6 \mathrm{~b}$ shows that the concentration of the surfactant does not have a significant effect on the Aphron fluid filtration depth through the porous medium.

\subsection{Effect of Bubble and Grain Size Range}

The five cases, which are listed in Table 3, are used to investigate the effect of Aphron bubble and rock grain size range. The results are shown in Figure 7. Figure 7 shows the results of the modeling for cases in which the range of grain size is between 1 to $100 \mu \mathrm{m}$. Figure 7a shows the concentration of the surfactant in a fixed point in the core (i.e. $2 \mathrm{~cm}$ ) during time. It shows that the fluid with small bubbles can filtrate in a much greater depth of the core. Assume two bubble size ranges, 1-100 $\mu \mathrm{m}$ and 1-25 $\mu \mathrm{m}$. The surfactant concentration for these two cases in 120 min injection, reaches 0.6 and $0.97 \mathrm{~g} / 350 \mathrm{cc}$, respectively. As shown in Figure $7 \mathrm{~b}$, increasing the bubble sizes would decrease the invaded zone, i.e. when bubble size varies between 1-100 $\mu \mathrm{m}$, the fluid filtration length (invaded zone depth) at a time of 2 min was $10 \mathrm{~cm}$, whereas, the fluid with a bubble size range between $1-25 \mu \mathrm{m}$, was invaded to a depth of $18 \mathrm{~cm}$ at the same time. Generally speaking, when bubbles are small in comparison to rock grains, the resistivity against filtration is decreased.

Figure 8 shows the effect of the grain size range on the Aphron fluid filtration, in a constant bubble size range of the fluid. Considering this figure, the rock with the small 
grain size can reduce the filtration of the Aphron fluid through the core. Comparing Figures 7 and 8, we can conclude that the size range of the bubble and grain must be taken into account simultaneously for predicting the filtration depth. In fact, the ratio of bubble size to grain size plays the main role in the flow of the Aphron fluid through the porous medium.

\subsection{Effect of Temperature}

Figure 9 shows the effect of temperature on Aphron fluid flow through the porous medium. It shows that increasing the temperature increases the filtration of the fluid, relatively. Increasing temperature will increase both bubble size and interfacial mass transport coefficients. Increasing bubble size will reduce the filtration, whereas, any increase in the interfacial mass transport, will increase the mass transport from the bubble to bulk fluid and reduce the bubble size due to dissolution. But note that, since there are layers of surfactant around the air core of the Aphron (rigid bubbles), the increase in bubble size due to temperature is negligible in comparison to bubble size reduction by the mass transfer. This means the main effect of temperature is on the transport coefficient.

\subsection{Effect of Pressure Difference}

Four cases which are listed in Table 4 are used to investigate the effect of pressure on filtration of the Aphron fluid through porous medium. The pressure behavior in the porous medium for different cases of Table 4 is shown in Figure 10. This pressure is used for estimation of bubble size, including effects of temperature and diffusion. Figure 11 shows the effect of the pressure difference on filtration of the Aphron fluid through the porous medium. According to Figure 11, the invaded zone thickness increases with pressure difference. Since the air core of the Aphron bubbles is compressible, the pressure increase will compress the bubble and reduce its size. Also, the high-pressure difference will give a high driving force for flow in the porous medium. At low-pressure 
differences, the low driving force and increasing bubble size due to expansion of the air core will reduce the invasion.

\subsection{Effect of the Medium Effective Porosity and Permeability}

For investigating the effect of the medium porosity and permeability, four porosity and four permeability values including, " $5 \%, 10 \%, 20 \%, 30 \%$ " and " $1 \mathrm{md}, 5 \mathrm{md}, 10 \mathrm{md}$, $100 \mathrm{md}$ " are considered, respectively. Figure 12 shows the effect of porosity on the filtration of Aphron fluid through the porous medium. According to Figure 12a, during time, concentration of the porous medium in a specified point of the core increases

gradually due to fluid invasion. This concentration increases with effective porosity. Figure $12 \mathrm{~b}$ shows that filtration length increases with increasing the effective porosity of the porous medium. It is noteworthy that the relation between porosity and concentration is not linear.

Figure 13 shows the pressure distribution for different values of the rock permeability. According to this, we can say that when the permeability of the rock is high, the pressure wave can proceed in a long distance through the rock. For example, when the permeability of the rock was $1 \mathrm{md}$ the pressure wave reached $16 \mathrm{~cm}$ of the rock, whilst, for permeability of $100 \mathrm{md}$ for the rock, the pressure wave reaches the end of the rock at the same time. Figure 14 shows the invasion length of the fluid for various permeability values. This figure shows the invasion length of the fluid increase with permeability. In fact, increasing permeability of the rock decreases the resistance of rock against a fluid flowing through the porous medium.

\section{Conclusion}

A mathematic model was developed as a special case of filtration theory for predicting Aphron transport in porous medium and the following conclusions were obtained: 
- The most important controlling parameter of the Aphron fluid invasion to the porous medium is the ratio of the bubble size to the grain size. Increasing this ratio decreases the invaded zone length.

- Temperature mainly affects the interfacial mass transport coefficients. These coefficients increase with temperature, and result in reducing bubble size and more filtration to the porous medium.

- Increasing the difference between injection pressure and pore pressure as a driving force increases the filtration of the fluid to the rock.

- The permeability and effective porosity effects are similar to each other, and increasing these values increase the filtration length and vice versa.

\section{Nomenclatures}

C Instant Surfactant/Aphron Concentration

$C_{0} \quad$ Inflow Concentration

$D$ Diffusion/Dispersion Coefficient

$k_{j} \quad$ Interfacial Mass Transport Coefficients of jth Layer

$N_{A} \quad$ Mass Flux

$m$ Partitioning Coefficient

$K \quad$ Langmuir Equilibrium Constant

$R^{\prime} \quad$ Gas Constant

$V \quad$ Volume

$S \quad$ Sutherland's Constant

$T$ Temperature

$P \quad$ Pressure

$T_{0} \quad$ Reference Temperature

$t \quad$ Time

$x \quad$ Space (linear)

$r \quad$ Space (radial)

$R \quad$ Retardation coefficient

$k_{1} \quad$ Distribution constant

$t_{0} \quad$ Aphron pulse injection duration time

$k_{a} \quad$ Pseudo first-order rate coefficient

$d_{g} \quad$ Equivalent Grain Diameter

$d_{p} \quad$ Bubble (Particle) Diameter

$U \quad$ Fluid Approaching Velocity

$k \quad$ Boltzmann Constant

$U_{p} \quad$ Particle Setteling Velocity 


$\begin{array}{cl}H & \text { Hamakar Constant } \\ N_{t} & \text { Number of Discretization in Time } \\ N_{x} & \text { Number of Grids in Space } \\ g & \text { Gravitational Acceleration } \\ t i & \text { Time Counter } \\ x i & \text { Space Counter }\end{array}$

Greek Letters

$\sigma_{0} \quad$ Surface Tension

$\Gamma_{m} \quad$ Maximum Reachable Surface Concentration

$\rho \quad$ Density

$\rho_{\text {bulk }}$ Density of the Dry Porous Medium

$\rho_{f} \quad$ fluid density

$\mu \quad$ Fluid Dynamic Viscosity

$\mu_{0} \quad$ Reference Viscosity

$\alpha_{L} \quad$ Longitudinal Dispersivity

$v_{0} \quad$ Velocity of the Pore Fluid

$\varepsilon \quad$ Porosity of the Porous Medium

$\lambda \quad$ Filtration Coefficient

$\eta \quad$ Porous Medium Efficiency

$\alpha \quad$ Collision Efficiency Factor

\section{Acknowledgment}

We thank Iran National Science Foundation (INSF) for their support in the current study.

\section{References}

Ahmadi, M.A., Galedarzadeh, M., Shadizadeh, S.R., 2015. Colloidal gas aphron drilling fluid properties generated by natural surfactants: Experimental investigation. J. Nat. Gas Sci. $\quad$ Eng. $\quad 27, \quad$ Part $\quad 2, \quad 1109-1117$. doi:http://dx.doi.org/10.1016/j.jngse.2015.09.056

Alizadeh, A., Khamehchi, E., 2017. Numerical and experimental investigation of microbubble fluid infiltration in porous media. Colloid Polym. Sci. 295, 529-541. doi:10.1007/s00396-017-4028-6

Alizadeh, A., Khamehchi, E., 2016a. Stability Modeling of Water-Based Surfactant Covered Micro-bubble Fluids. J. Surfactants Deterg. 19, 165-171. 
doi:10.1007/s11743-015-1761-z

Alizadeh, A., Khamehchi, E., 2016b. Mathematical modeling of the colloidal gas aphron motion through porous medium, including colloidal bubble generation and destruction. Colloid Polym. Sci. 294, 1075-1085. doi:10.1007/s00396-016-3866-y

Alizadeh, A., Khamehchi, E., 2016c. Modeling of Micro-bubble Drilling Fluid Stability. LAP Lambert Academic Publishing, Germany.

Alizadeh, A., Khamehchi, E., 2015a. A model for predicting size distribution and liquid drainage from micro-bubble surfactant multi-layer fluids using population balance. Colloid Polym. Sci. 293, 3419-3427. doi:10.1007/s00396-015-3678-5

Alizadeh, A., Khamehchi, E., 2015b. Modeling of micro-bubble surfactant multi-layer drilling fluid stability based on single bubble behavior under pressure and temperature in a deviated gas well. J. Nat. Gas Sci. Eng. 26, 42-50. doi:http://dx.doi.org/10.1016/j.jngse.2015.05.027

Belkin, A., Irving, M., O\&apos;Connor, B., Fosdick, M., Hoff, T.L., Growcock, F.B., 2005. How Aphron Drilling Fluids Work. doi:10.2118/96145-MS

Bjorndalen, N., Kuru, E., 2008. Stability of Microbubble-Based Drilling Fluids Under Downhole Conditions. doi:10.2118/08-06-40

Brookey, T., 1998. "Micro-Bubbles": New Aphron Drill-In Fluid Technique Reduces Formation Damage in Horizontal Wells. doi:10.2118/39589-MS

Brookey, T., Rea, A., 2003. UBD and Beyond: Aphron Drilling Fluids for Depleted Zones, in: IADC 2003 World Drilling, June 25 - 26,. Vienna, Austria.

Golan, M., Whitson, C., 1991. Well Performance, 2nd ed. Prentice Hall, New Jersy.

Ivan, C.D., Quintana, J.L., Blake, L.D., 2001. Aphron-Base Drilling Fluid: Evolving Technologies for Lost Circulation Control. doi:10.2118/71377-MS

Khamehchi, E., Tabibzadeh, S., Alizadeh, A., 2016. Rheological properties of Aphron based drilling fluids. Pet. Explor. Dev. 43, 1076-1081. doi:http://dx.doi.org/10.1016/S1876-3804(16)30125-2

Martinus Th. Van Genuchten, WJ Alves, 1982. Analytical Solutions of One Dimensional Convective Dispersive Solute Transport Equations. U.S. Department of Agriculture, 
Washington, DC.

Rajagopalan, R., Tien, C., 1976. Trajectory analysis of deep-bed filtration with the sphere-in-cell porous media model. AIChE J. 22, 523-533. doi:10.1002/aic.690220316

Ramirez, F., Greaves, R., Montilva, J., 2002. Experience Using Microbubbles-Aphron Drilling Fluid in Mature Reservoirs of Lake Maracaibo. doi:10.2118/73710-MS

Rea, A.B., Alvis, E.C., Paiuk, B.P., Climaco, J.M., Vallejo, M., Leon, E., Inojosa, J., 2003. Application of Aphrons Technology in Drilling Depleted Mature Fields. doi:10.2118/81082-MS

Samuel, S.R., Kuru, E., Trivedi, J.J., 2012. Design and Development of Aqueous Colloidal Gas Aphrons for Enhanced Oil Recovery Applications. doi:10.2118/154518-MS

Sebba, F., 1987. Foams and Biliquid Foams - Aphrons. John Wiley \& Sons Ltd, Chichester.

Selim, H.M., Mansell, R.S., 1976. Analytical solution of the equation for transport of reactive solutes through soils. Water Resour. Res. 12, 528-532. doi:10.1029/WR012i003p00528

Smits, A., Dussauge, J.-P., 2006. Turbulent Shear Layers in Supersonic Flow.

Suhas Patankar, 1980. Numerical Heat Transfer and Fluid Flow. John Wiley \& Sons Ltd.

Wang, S., Wei, T., Chen.WB, Tsao, H., 2004. Effects of surfactant micelles on viscosity and conductivity of poly(ethylene glycol) solutions. Journaol Chem. Phys. 10, 4980. doi:10.1063/1.1644798

White, C.C., Chesters, A.P., Ivan, C.D., Maikranz, S., Nouris, R., 2003. Aphron-based Drilling Fluid: Novel Technology for Drilling Depleted Formations in the North Sea. doi:10.2118/79840-MS

Yao, K.-M., Habibian, M., O'melia, C., 1971. Water and Waste Water Filtration: Concepts and Applications. Environ. Sci. Technol. 5, 1105-1112. 


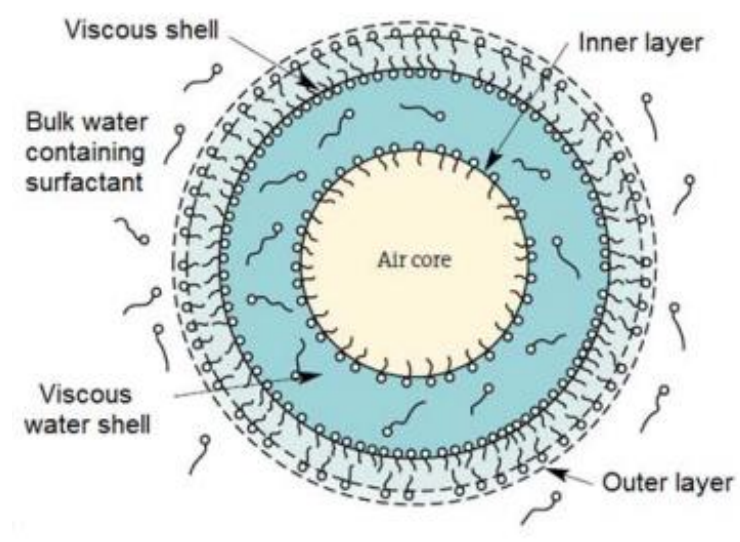

(a)

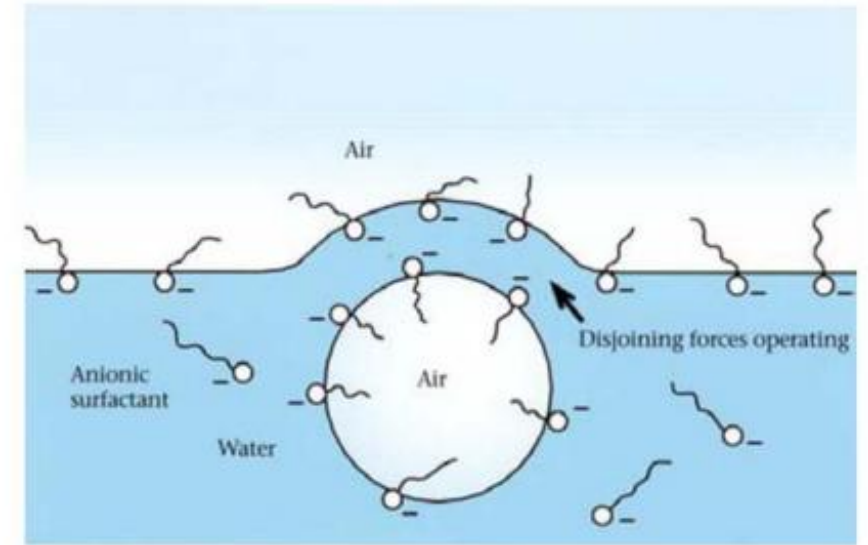

(b)

Figure 1. a) Aphron Single Bubble Structure, b) Conventional Foam Bubble Structure (Sebba, 1987)

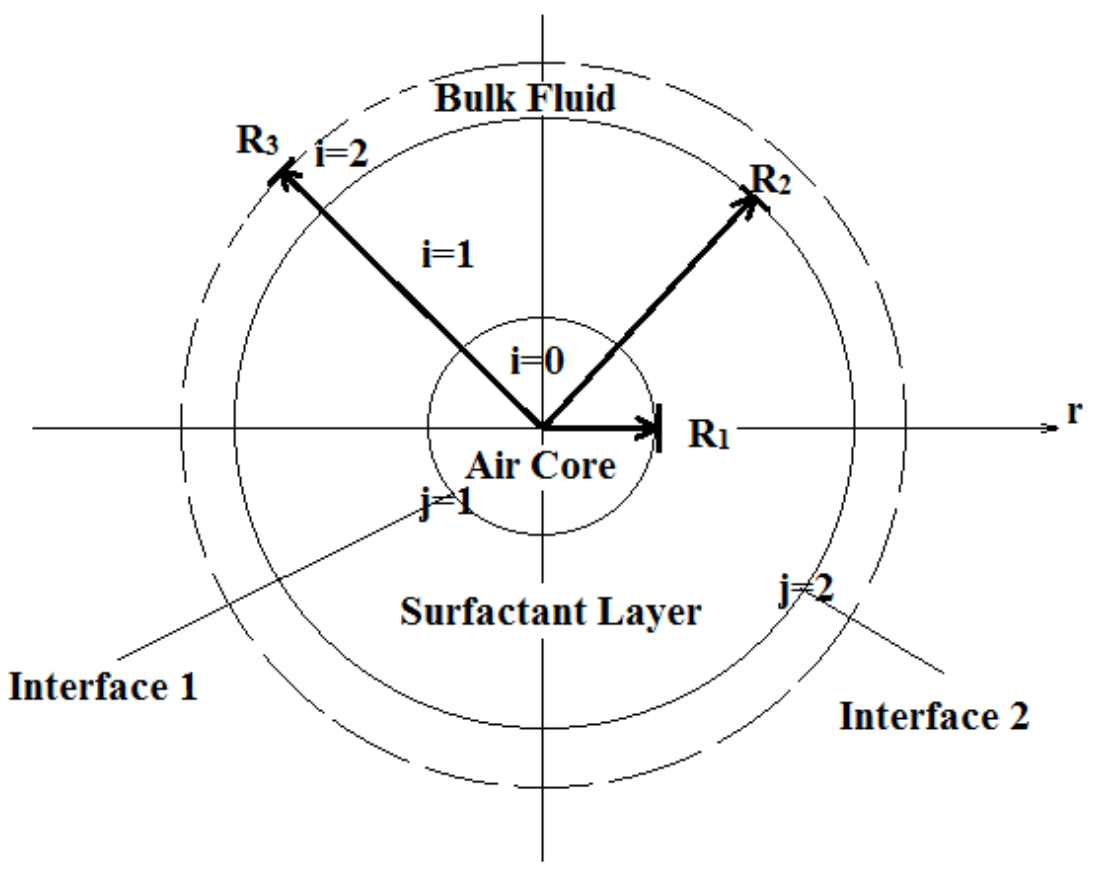

Figure 2. Aphron Bubble Scheme 


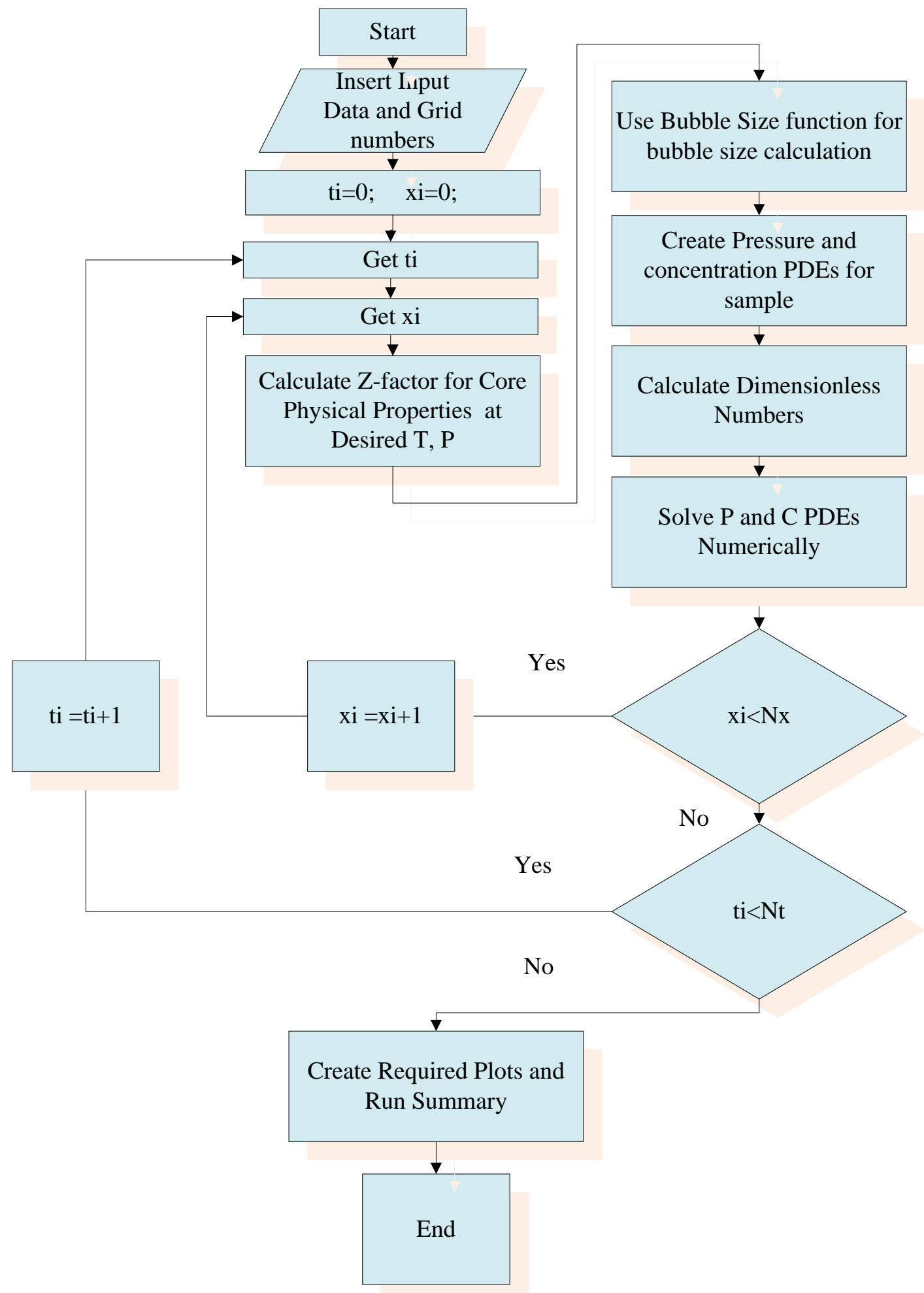

Figure 3. Flowchart of the Solution 


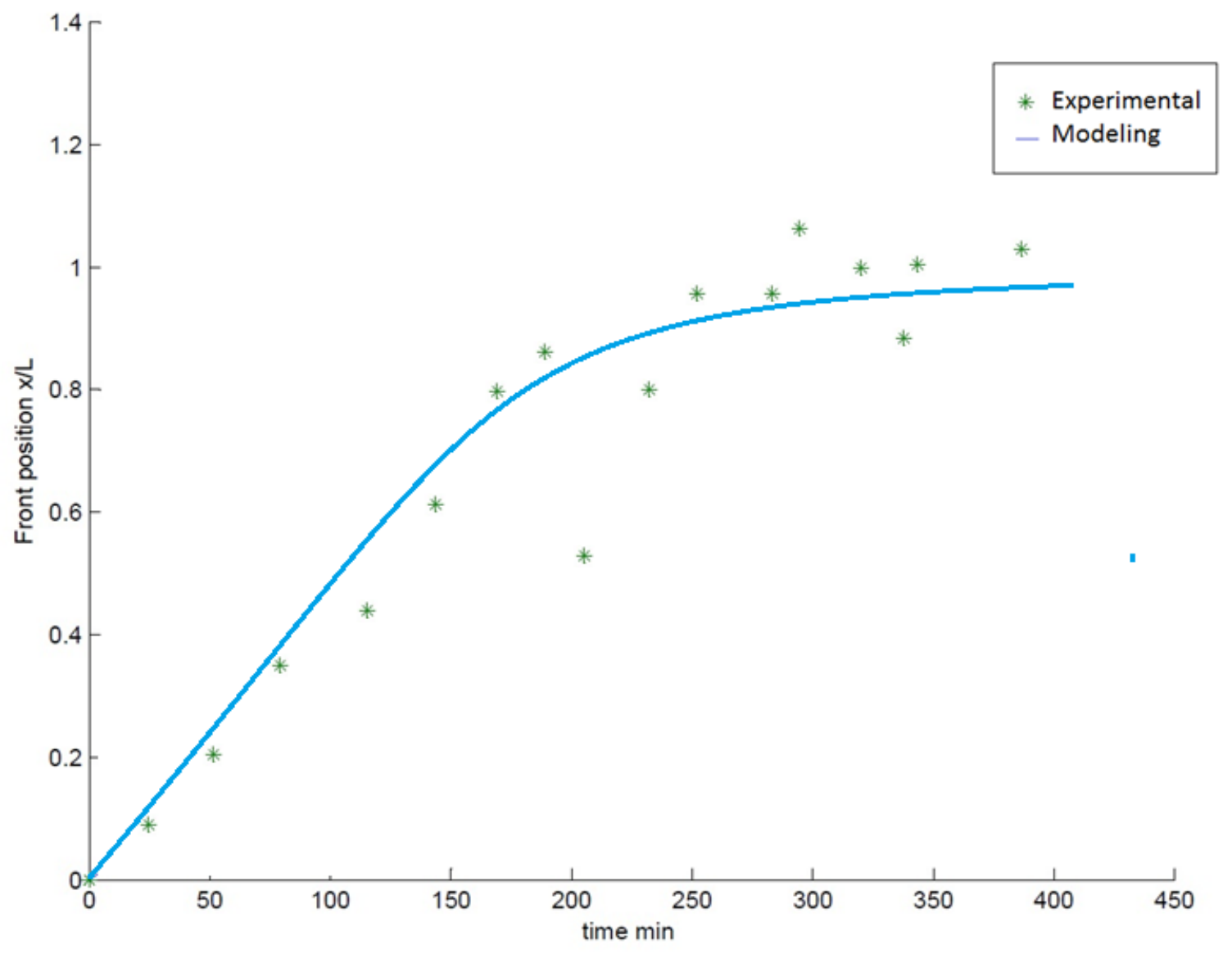

Figure 4. Experimental infiltration [24] versus Modeling Results 


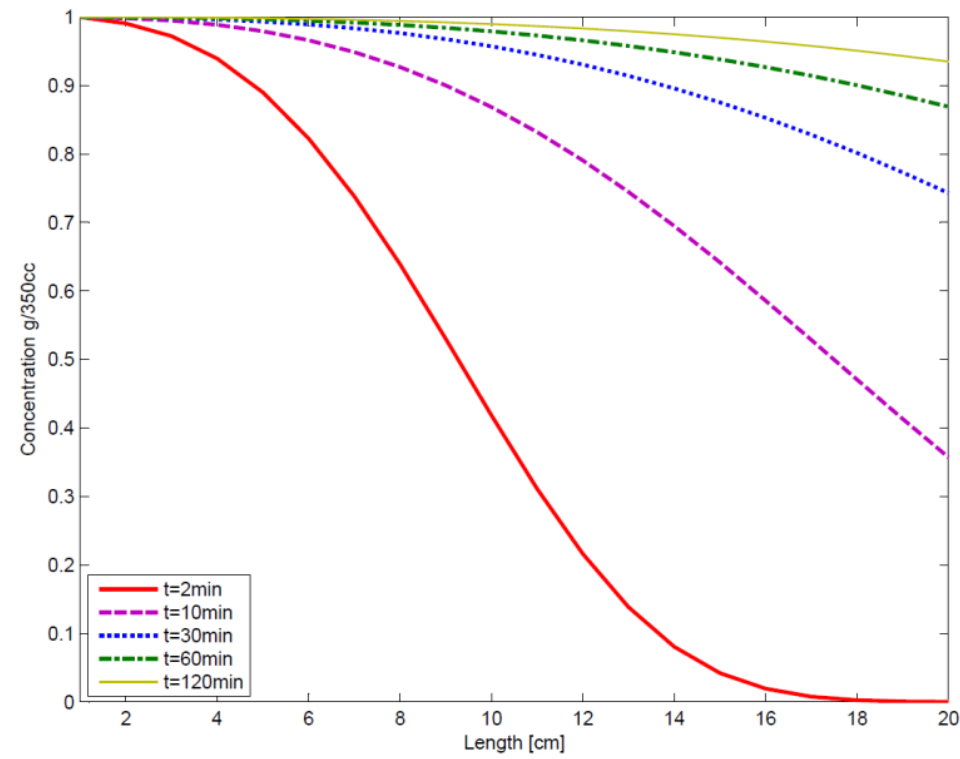

Figure 5. Surfactant Concentration Distribution through Porous Medium, Injecting 1g/350cc Surfactant
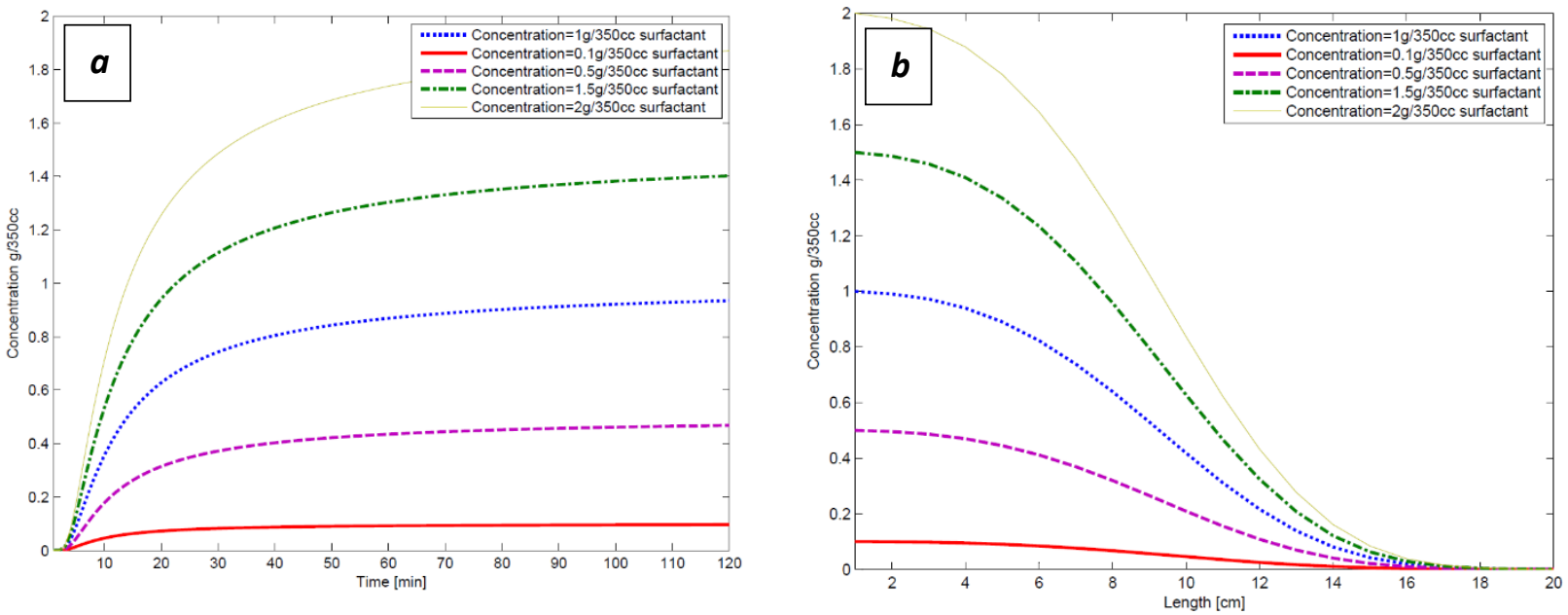

Figure 6. Surfactant Concentration Variation , $a$ ) in $\mathrm{x}=2 \mathrm{~cm}$ of the Porous Medium, $b$ ) in $\mathrm{t}=2 \mathrm{~min}$ 

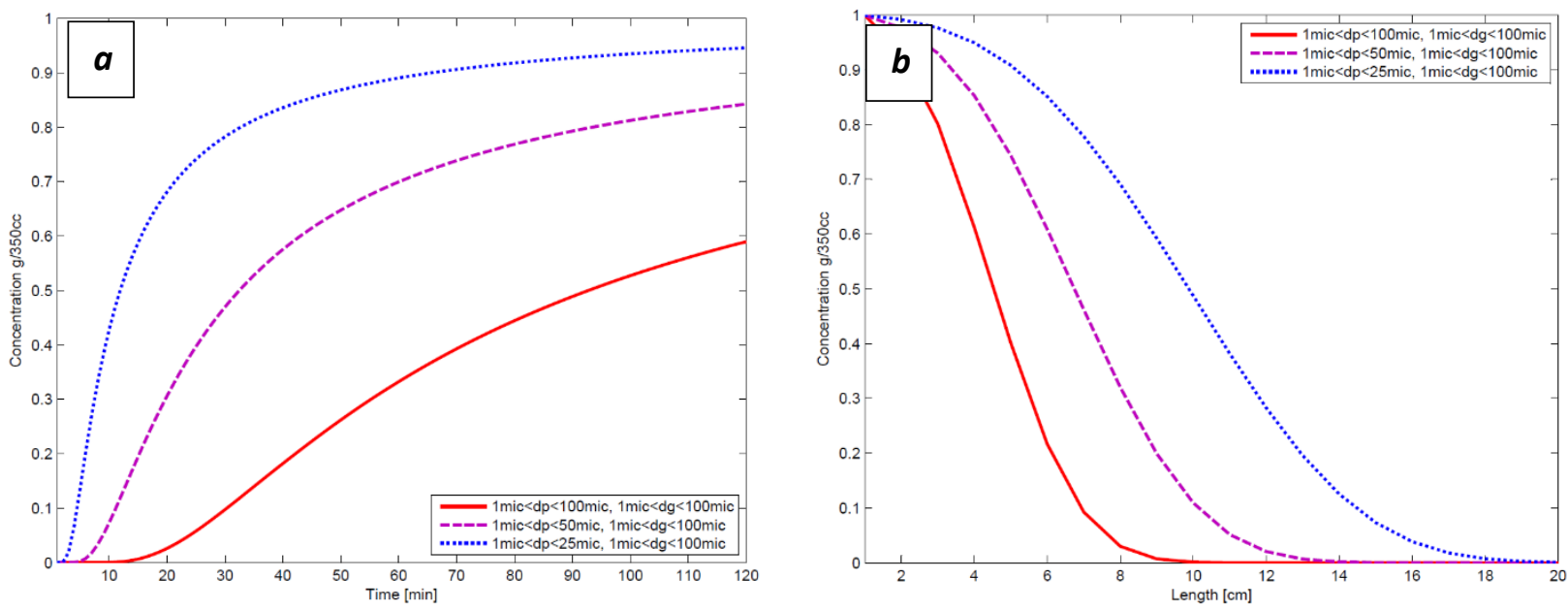

Figure 7. Effect of Bubble Size Range on Filtration of the Fluid through Porous medium , $a$ ) in $\mathrm{x}=\mathbf{2 \mathrm { cm }}$ of the Porous Medium, $b$ ) in $\mathrm{t}=\mathbf{2} \mathrm{min}$
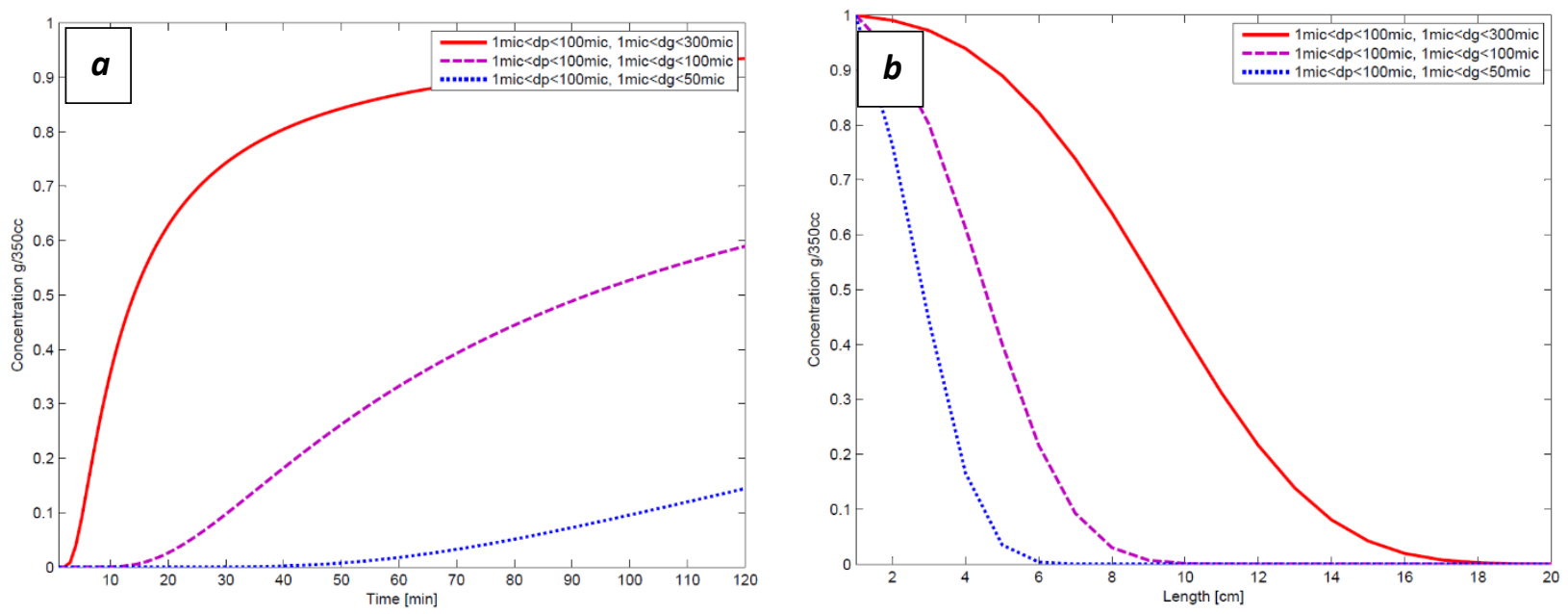

Figure 8. Effect of Grain Size Range on Filtration of the Fluid through Porous medium , $a$ ) in $\mathrm{x}=\mathbf{2 \mathrm { cm }}$ of the Porous Medium, $b$ ) in $\mathrm{t}=\mathbf{2} \mathrm{min}$ 


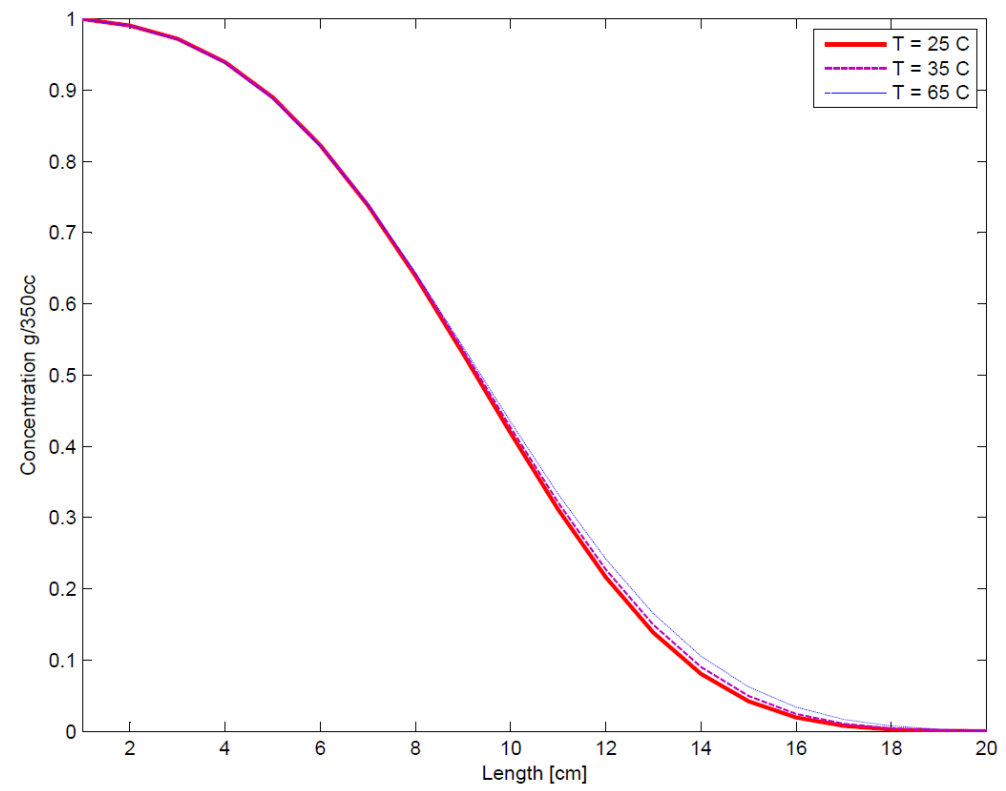

Figure 9. Effect of Temperature on Filtration of the Fluid through Porous Medium, $t=2 \mathrm{~min}$
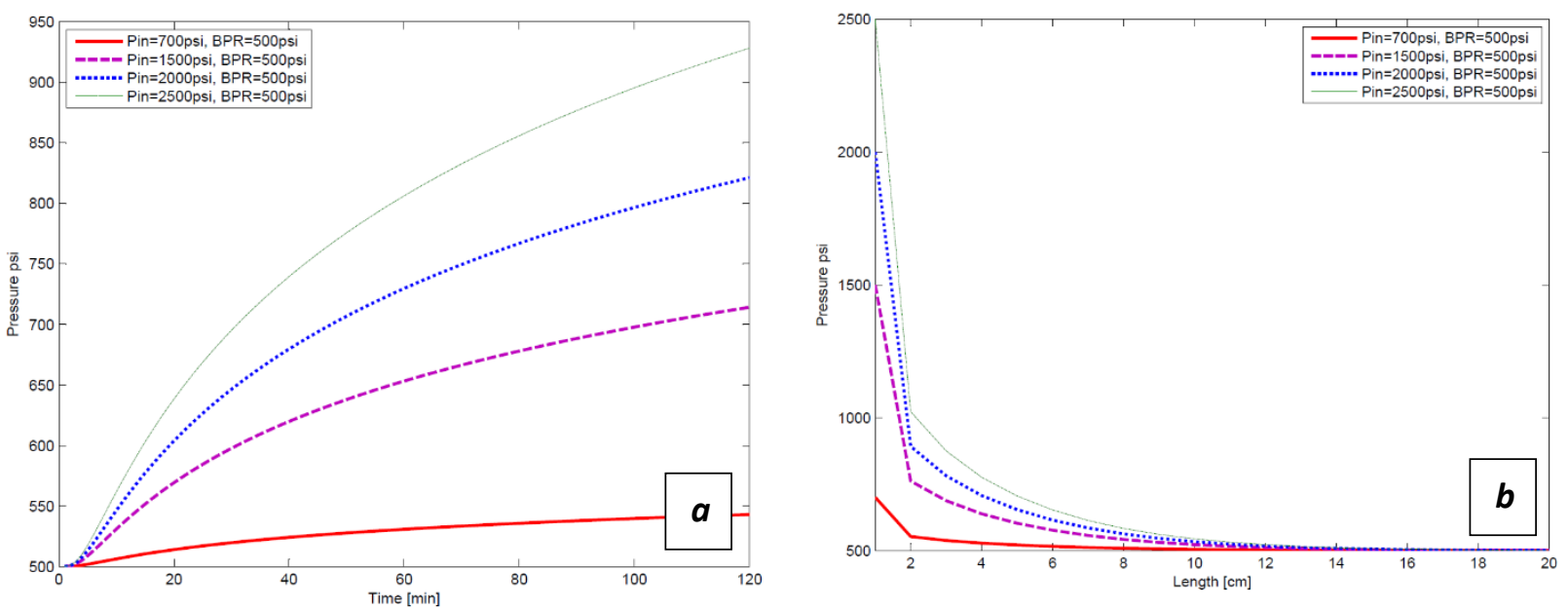

Figure 10. Pressure Behavior in the Porous medium During Injection of the Aphron Fluid, $a$ ) in $\mathrm{x}=\mathbf{2} \mathrm{cm}$ of the Porous Medium, $b$ ) in $\mathrm{t}=2 \mathrm{~min}$ 

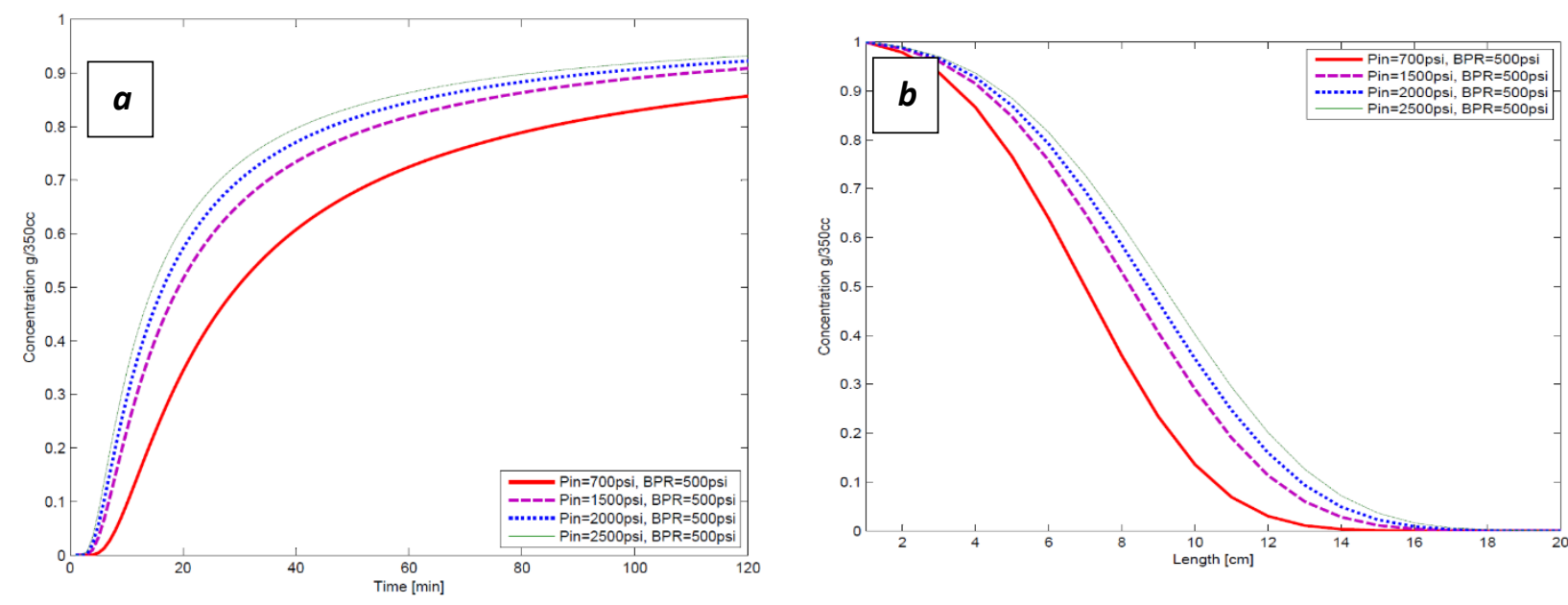

Figure 11. Effect of Pressure Difference on Filtration of the Fluid through Porous Medium , $a$ ) in $\mathrm{x}=\mathbf{2 \mathrm { cm }}$ of the Porous Medium, $b$ ) in $\mathrm{t}=\mathbf{2} \mathrm{min}$
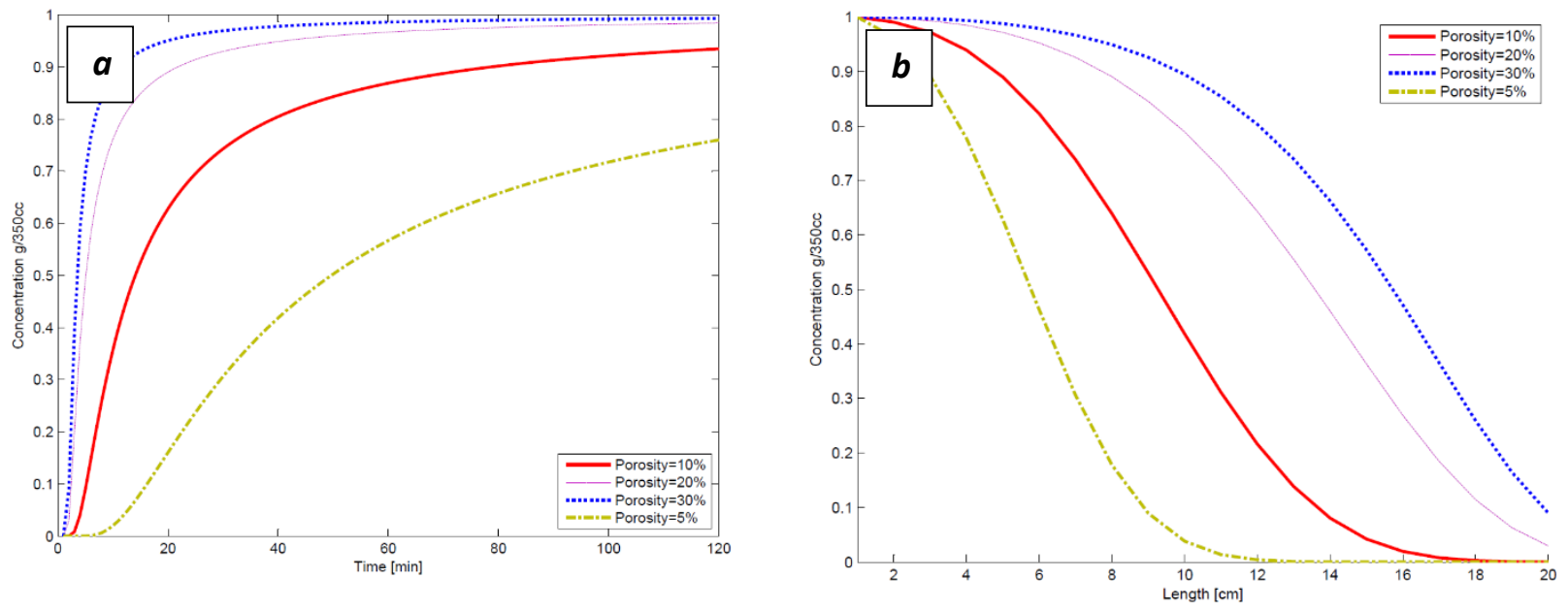

Figure 12. Effect of Porosity on Filtration of the Fluid through Porous medium , $a$ ) in $x=2 \mathrm{~cm}$ of the Porous Medium, $b$ ) in $\mathrm{t}=\mathbf{2 m i n}$ 

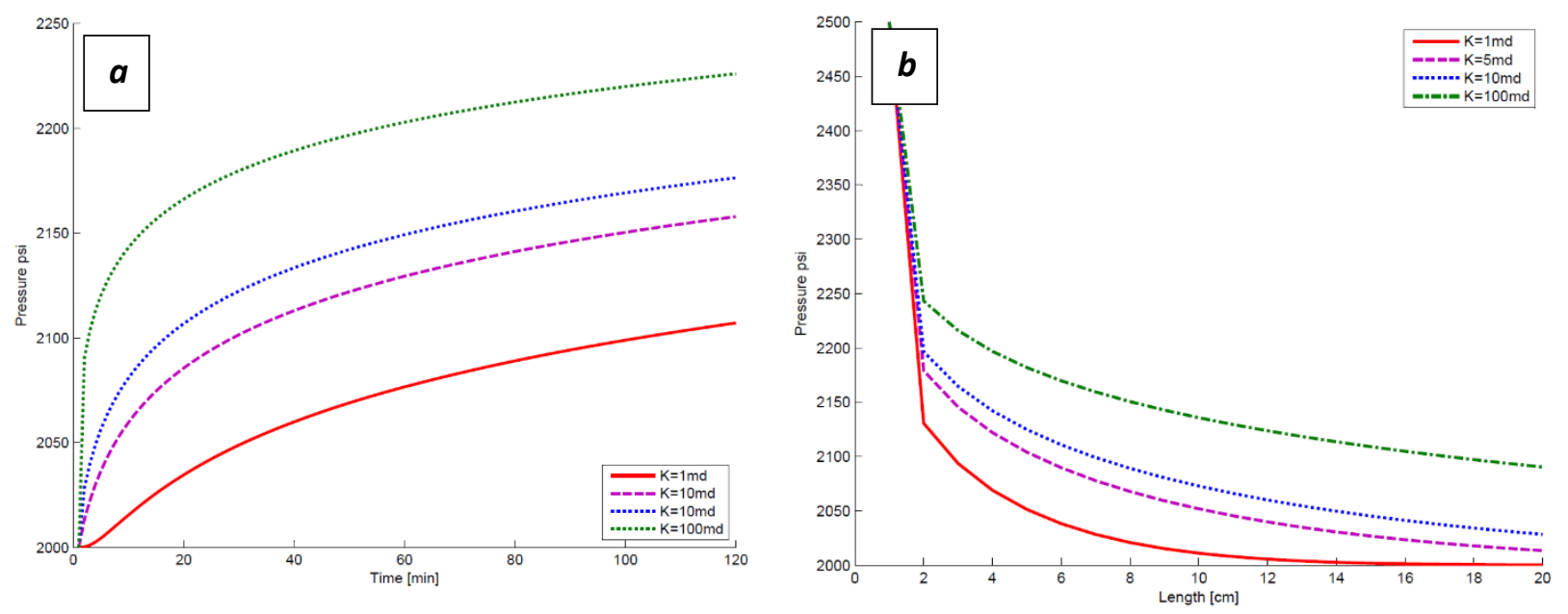

Figure 13. Effect of Permeability on Pressure Distribution of the Fluid through Porous medium , $a$ ) in $\mathrm{x}=2 \mathrm{~cm}$ of the Porous Medium, $b$ ) in $\mathrm{t}=2 \mathrm{~min}$
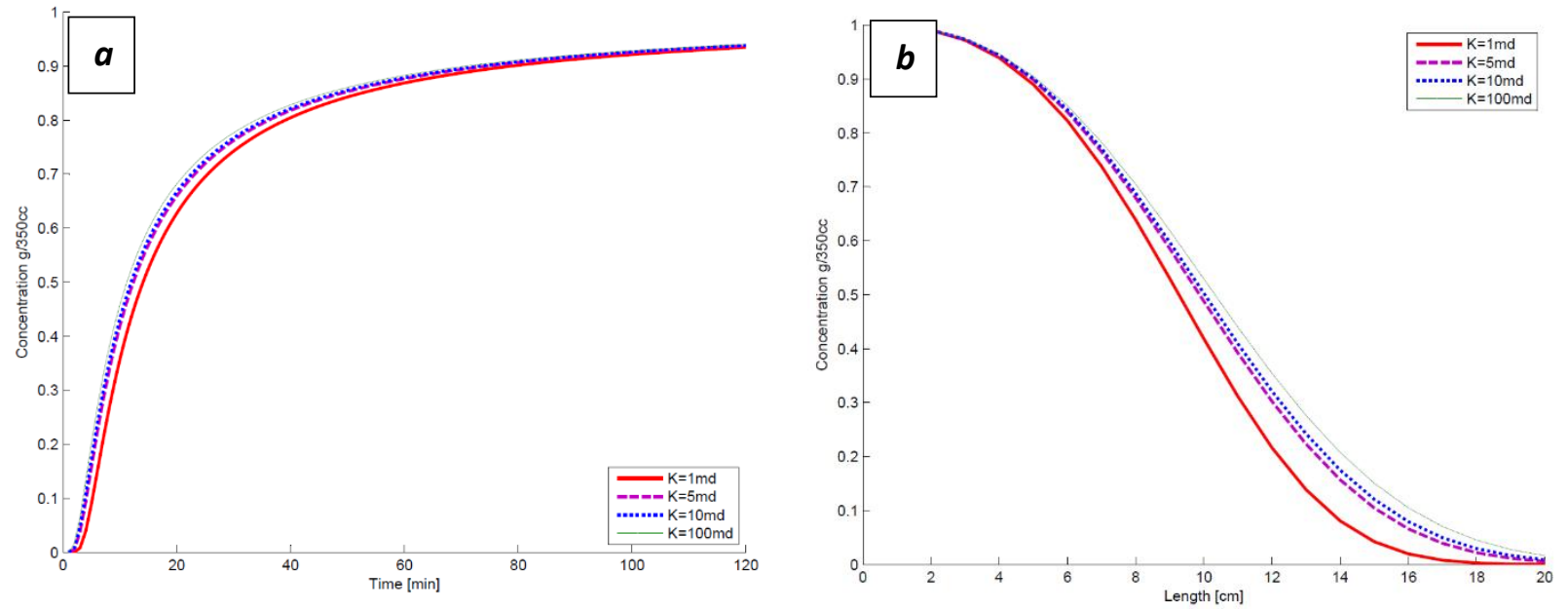

Figure 14. Effect of Permeability on Filtration of the Fluid through Porous medium , $a$ ) in $x=2 \mathrm{~cm}$ of the Porous Medium, $b$ ) in $t=2 \mathrm{~min}$ 
Table 1. Initial and Boundary Conditions of the Mass Transfer Partial Difference Equations

\begin{tabular}{ccc}
\hline i, index & Initial Conditions & Boundary Conditions \\
\hline 0 & $\mathrm{C}_{\mathrm{i}}=\mathrm{C}_{\mathrm{i}, 0} / \mathrm{m}^{*}$ & $\left(\frac{\partial \mathrm{C}_{\mathrm{Ac}}}{\partial \mathrm{r}}\right)_{\mathrm{r}=0}=0$ for $\mathrm{r}=0$ \\
1 & $\mathrm{C}_{\mathrm{i}}=0$ & Equation 2, for $\mathrm{j}=1,2$ \\
2 & $\left(\frac{\partial \mathrm{C}_{\mathrm{i}}}{\partial \mathrm{r}}\right)_{\mathrm{r}=\mathrm{R}_{3}}=0$ for $\mathrm{r}=\mathrm{R}_{3}$ \\
\hline
\end{tabular}

* m: partitioning coefficient

Table 2. Base Case Properties

\begin{tabular}{lc|lc}
\hline \multicolumn{1}{c}{ Parameter } & Value & \multicolumn{1}{c}{ Parameter } & Value \\
\hline Surfactant concentration & $1 \mathrm{~g} / 350 \mathrm{cc}$ & Water viscosity & $1 \mathrm{cp}$ \\
$\mathrm{CMC}^{*}$ of the surfactant & $6 \mathrm{~g} / \mathrm{l}$ & Core length & $20 \mathrm{~cm}$ \\
Injection Pressure & $2500 \mathrm{psi}$ & Core diameter & $3.81 \mathrm{~cm}$ \\
Back pressure & $2000 \mathrm{psi}$ & Porosity & $10 \%$ \\
Temperature & $25 \mathrm{C}$ & Permeability & $1 \mathrm{md}$ \\
Bubble size range & $1-100 \mu \mathrm{m}$ & Collision efficiency factor & $7.1 * 10^{-5}$ \\
Grain size range & $1-300 \mu \mathrm{m}$ & Gravitational acceleration & $9.81 \mathrm{~m} / \mathrm{s}^{2}$ \\
\hline
\end{tabular}

"CMC: Critical Micelle Concentration

Table 3. Five Cases for Investigating the Effect of the Bubble and Grain Size Range on the Fluid Filtration through Porous medium

\begin{tabular}{ccc}
\hline Case & Bubble Size & Grain Size \\
\hline 1 & $1-100 \mu \mathrm{m}$ & $1-300 \mu \mathrm{m}$ \\
2 & $1-100 \mu \mathrm{m}$ & $1-100 \mu \mathrm{m}$ \\
3 & $1-100 \mu \mathrm{m}$ & $1-50 \mu \mathrm{m}$ \\
4 & $1-50 \mu \mathrm{m}$ & $1-100 \mu \mathrm{m}$ \\
5 & $1-25 \mu \mathrm{m}$ & $1-100 \mu \mathrm{m}$ \\
\hline
\end{tabular}


Table 4. Four Cases for Investigating the Effect of Pressure on the Fluid Filtration through Porous medium

\begin{tabular}{ccc}
\hline Injection Pressure (psi) & Back Pressure (psi) & $\Delta \mathbf{P}(\mathbf{p s i})$ \\
\hline 700 & 500 & 200 \\
1500 & 500 & 1000 \\
2000 & 500 & 1500 \\
2500 & 500 & 2000 \\
\hline
\end{tabular}

